
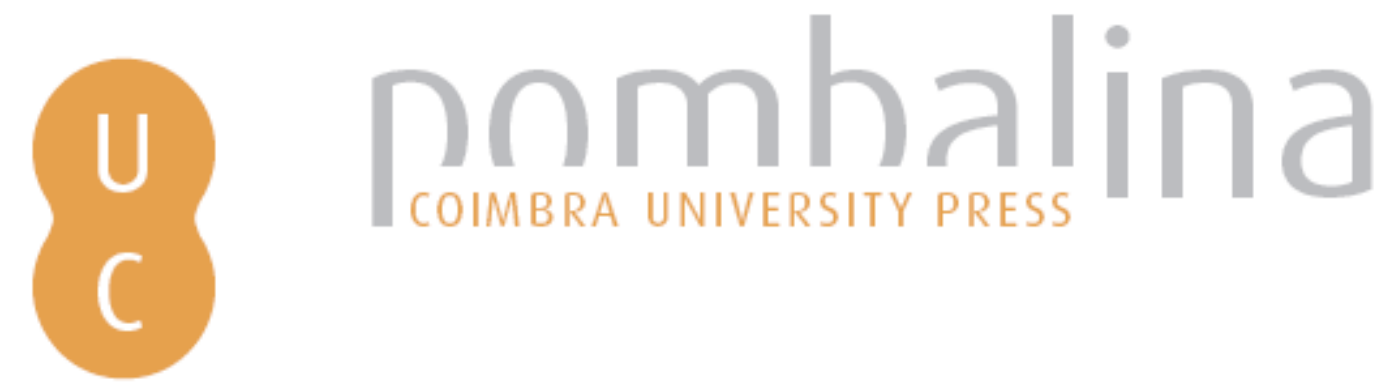

\title{
Do carvalho ao castanheiro: usos e propriedades medicinais de fagáceas nas Enarrationes de Amato Lusitano
}

\author{
Autor(es): Oliveira, Emília
}

Publicado por: UA Editora - Universidade de Aveiro; Imprensa da Universidade de

URL persistente:

URI:http://hdl.handle.net/10316.2/35701

DOI:

DOl:http://dx.doi.org/10.14195/978-989-26-0941-6_15

Accessed : $\quad$ 26-Apr-2023 14:14:27

A navegação consulta e descarregamento dos títulos inseridos nas Bibliotecas Digitais UC Digitalis, UC Pombalina e UC Impactum, pressupõem a aceitação plena e sem reservas dos Termos e Condições de Uso destas Bibliotecas Digitais, disponíveis em https://digitalis.uc.pt/pt-pt/termos.

Conforme exposto nos referidos Termos e Condições de Uso, o descarregamento de títulos de acesso restrito requer uma licença válida de autorização devendo o utilizador aceder ao(s) documento(s) a partir de um endereço de IP da instituição detentora da supramencionada licença.

Ao utilizador é apenas permitido o descarregamento para uso pessoal, pelo que o emprego do(s) título(s) descarregado(s) para outro fim, designadamente comercial, carece de autorização do respetivo autor ou editor da obra.

Na medida em que todas as obras da UC Digitalis se encontram protegidas pelo Código do Direito de Autor e Direitos Conexos e demais legislação aplicável, toda a cópia, parcial ou total, deste documento, nos casos em que é legalmente admitida, deverá conter ou fazer-se acompanhar por este aviso.

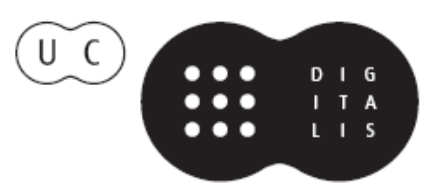




\section{HUMANISMO E CIÊNCIA Antiguidade e Renascimento}

António Manuel Lopes Andrade

Carlos de Miguel Mora

João Manuel Nunes Torrão
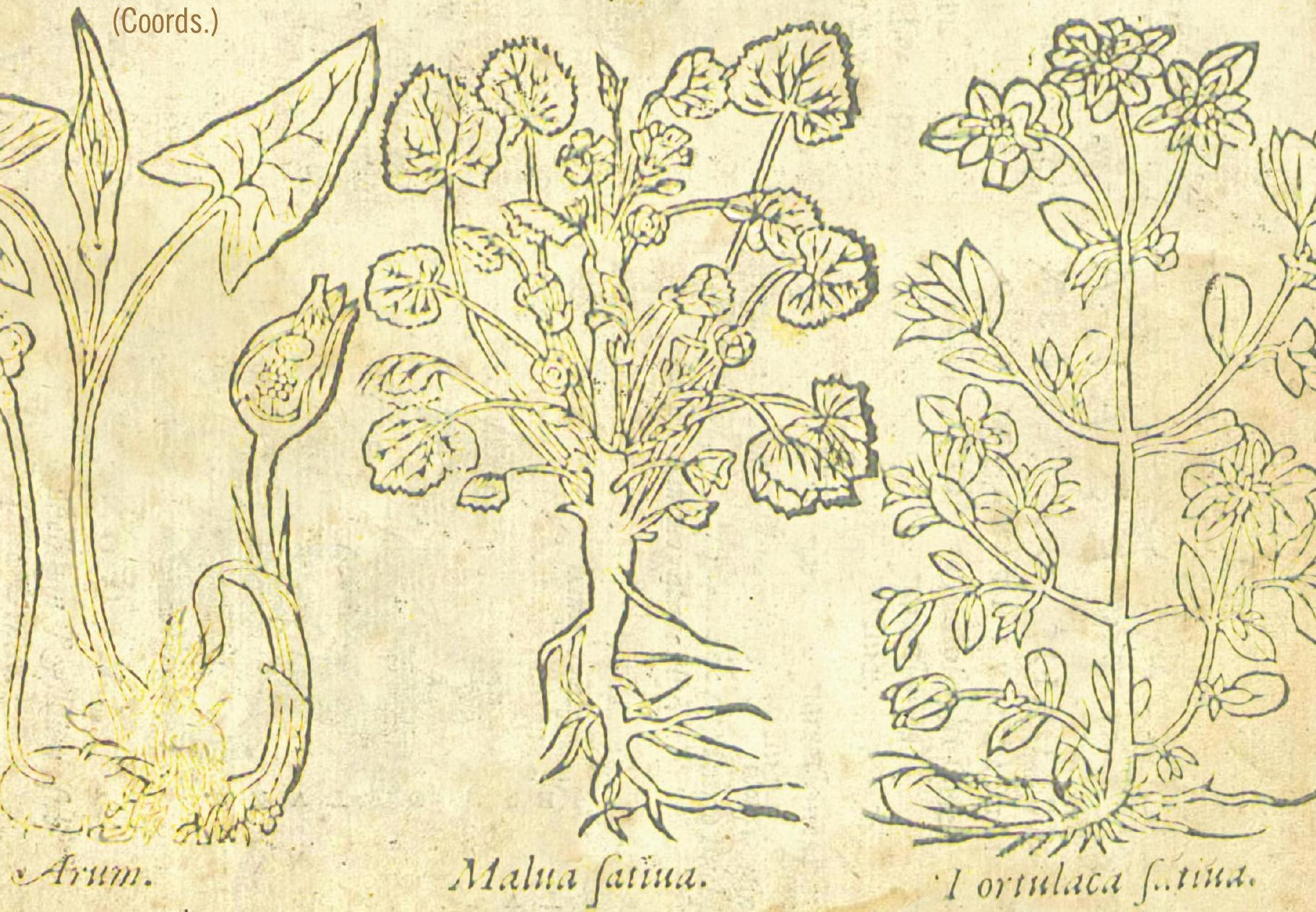

Aveiro I Coimbra I São Paulo 2015

UA Editora - Universidade de Aveiro I Imprensa da Universidade de Coimbra I Annablume 
Este volume resulta de várias iniciativas desenvolvidas no âmbito do projecto de I\&D "Dioscórides e o Humanismo Português: os Comentários de Amato Lusitano" (http://amatolusitano.web.ua.pt), recoIhendo contribuições de mais de duas dezenas de colaboradores, tanto de membros da equipa como de outros investigadores nacionais e estrangeiros. Entre os eventos que estiveram na origem deste livro destacam-se as três edições do Ciclo de Conferências promovido pelo projecto, realizadas entre 2010 e 2013, e sobretudo o Colóquio Internacional "Dioscórides e o Humanismo Português: os Comentários de Amato Lusitano", que decorreu no Departamento de Línguas e Culturas da Universidade de Aveiro, nos dias 21 e 22 de Novembro de 2013.

0 objectivo principal do projecto é a edição e tradução para português dos dois livros que Amato Lusitano dedicou ao comentário do tratado grego De materia medica de Dioscórides, ou seja, o Index Dioscoridis (Antuérpia, 1536) e as In Dioscoridlis Anazarbei de medica materia libros quinque... enarrationes (Veneza, 1553), estando contemplada, também, a tradução de mais duas obras directamente correlacionadas com os livros do médico português: a montante, a do próprio tratado grego de Dioscórides; a jusante, a do livro intitulado Apologia adversus Amathum Lusitanum (Veneza, 1558) de Pietro Andrea Mattioli.

OBRA PUBLICADA COM A COORDENAÇÃO

CIENTÍFICA DE:

Centro de Línguas, Literaturas e Culturas da Universidade de Aveiro

Centro de Estudos Clássicos e Humanísticos da Universidade de Coimbra

Cátedra de Estudos Sefarditas "Alberto

Benveniste" da Faculdade de Letras da Universidade de Lisboa 


\section{HUMANISMO E CIÊNCIA}

\section{Antiguidade e Renascimento}

ANTÓNIO MANUEL LOPES ANDRADE

CARLOS DE MIGUEL MORA

JOÃO MANUEL NUNES TORRÃO

(COORDS.)

AVEIRO • COIMBRA • SÃO PAULO

2015

UA EDITORA • UNIVERSIDADE DE AVEIRO

IMPRENSA DA UNIVERSIDADE DE COIMBRA

ANNABLUME 


\section{HUMANISMO E CIÊNCIA: Antiguidade e Renascimento}

\author{
EDIÇÃO

UA EDITORA • UNIVERSIDADE DE AVEIRO
IMPRENSA DA UNIVERSIDADE DE COIMBRA
ANNABLUME

ORGANIZAÇÃO E COORDENAÇÃO EDITORIAL ANTÓNIO MANUEL LOPES ANDRADE

CARLOS DE MIGUEL MORA

JOÃO MANUEL NUNES TORRÃO

\author{
DESIGN DA CAPA \\ MEIOKILO DESIGN STUDIO
}

DESIGN

CARLOS COSTA

IMPRESSÃO E ACABAMENTO

SERSILITO • MAIA

ISBN

UA • 978-972-789-434-5

IUC • 978-989-26-0940-9

\section{ISBN DIGITAL}

UA • 978-972-789-435-2

IUC • 978-989-26-0941-6

DOI

http://dx.doi.org/10.14195/ 978-989-26-0941-6

DEPÓSITO LEGAL 368241/13

TIRAGEM 500 Exemplares

(C) 2015

UA EDITORA • UNIVERSIDADE DE AVEIRO IMPRENSA DA UNIVERSIDADE DE COIMBRA

ANNABLUME

\section{COMISSÃO CIENTÍFICA}

António Manuel Lopes Andrade

Carlos de Miguel Mora

Delfim Ferreira Leão

Henrique Leitão

João Manuel Nunes Torrão

Maria de Fátima Reis

Maria do Céu Zambujo Fialho

Miguel Ángel González Manjarrés

\section{TEXTOS}

Adelino Cardoso

Ana Leonor Pereira

Ana Margarida Borges

António Guimarães Pinto

António Maria Martins Melo

Bernardo Mota

Carlos A. Martins de Jesus

Carlos de Miguel Mora

Cristina Santos Pinheiro

Donald Beecher

Emília Oliveira

Isabel Malaquias

James W. Nelson Novoa

Joana Mestre Costa

João Manuel Nunes Torrão

João Rui Pita

Jorge Paiva

José Sílvio Moreira Fernandes

Maria de Fátima Silva

Miguel Ángel González Manjarrés

Rui Manuel Loureiro

Telmo Corujo dos Reis

Teresa Nobre de Carvalho

Vinicije B. Lupis

Virgínia Soares Pereira 


\section{HUMANISMO E CIÊNCIA}

\section{Antiguidade e Renascimento}

ANTÓNIO MANUEL LOPES ANDRADE

CARLOS DE MIGUEL MORA

JOÃO MANUEL NUNES TORRÃO

(COORDS.)

AVEIRO • COIMBRA • SÃO PAULO

2015

UA EDITORA • UNIVERSIDADE DE AVEIRO

IMPRENSA DA UNIVERSIDADE DE COIMBRA

ANNABLUME 
OBRA PUBLICADA

COM A COORDENAÇÃO

CIENTÍFICA DE:

CENTRO DE LÍNGUAS,

LITERATURAS E CULTURAS DA

UNIVERSIDADE DE AVEIRO

CENTRO DE ESTUDOS

CLÁSSICOS E HUMANÍSTICOS DA

UNIVERSIDADE DE COIMBRA

CÁTEDRA DE ESTUDOS SEFARDITAS

"ALBERTO BENVENISTE"

DA FACULDADE DE LETRAS DA

UNIVERSIDADE DE LISBOA 


\section{SUMÁRIO}

PREFÁCIO

1.1 "Teofrasto, Tratado das plantas. No alvor de uma nova ciência" 13

Maria de Fátima Silva

1.2 "Francisco de Melo e os fragmentos de teoria óptica de Pierre Brissot" 21 Bernardo Mota

1.3 "Algumas reflexões sobre as pedras preciosas nos Colóquios dos simples de Garcia de Orta" 37 Rui Manuel Loureiro

1.4 "Estratégias, patronos e favores em Colóquios dos Simples de Garcia de Orta" 63 Teresa Nobre de Carvalho

1.5 "As plantas na obra poética de Camões (épica e lírica)" 95 Jorge Paiva

1.6 "Nicolás Monardes, John Frampton and the Medical Wonders of the New World" .141 Donald Beecher

1.7 "Literatura e Medicina: alguns textos de Justo Lípsio e de dois doutores Luís Nunes" 161 António Guimarães Pinto

1.8 "Ontologias e idiossincrasias dos Amantes, à luz da Archipathologia de Filipe Montalto" ...... 211 Joana Mestre Costa \& Adelino Cardoso

1.9 "Gabriel da Fonseca. A New Christian doctor in Bernini's Rome". .227 James W. Nelson Novoa 


\section{2) DIOSCÓRIDES E O HUMANISMO PORTUGUÊS: OS COMENTÁRIOS DE AMATO LUSITANO}

2.1 "Léxico científico português nos Comentários de Amato: antecedentes e receção"

Ana Margarida Borges

2.2 "Usos medicinais das plantas, em Amato Lusitano: o bálsamo"

António Maria Martins Melo

2.3 "Amato Lusitano e a importância da ilustração botânica no século xVI.

Em torno das edições lionesas das Enarrationes (1558)"

Carlos A. Martins de Jesus

2.4 "Sobre la identificación entre ébano y guayaco en una entrada

del Index Dioscoridis de Amato Lusitano".

Carlos de Miguel Mora

2.5 "Os partos distócicos em Amato Lusitano e em Rodrigo de Castro:

fontes, doutrinas e terapias greco-romanas"

\section{Cristina Santos Pinheiro}

2.6 "Do carvalho ao castanheiro: usos e propriedades medicinais

de fagáceas nas Enarrationes de Amato Lusitano".

Emília Oliveira

2.7 "O mundo mineral nos Comentários a Dioscórides de Amato Lusitano".

Isabel Malaquias \& Virgínia Soares Pereira

2.8 "Alguns comentários de Amato: entre a estranheza e a realidade"

João Manuel Nunes Torrão

2.9 "Caracterização e usos terapêuticos de produtos de origem marinha

nos Comentários de Amato Lusitano a Dioscórides"

José Sílvio Moreira Fernandes

2.10 "La mandrágora de Amato Lusitano: edición, traducción y anotación"

Miguel Ángel González Manjarrés

2.11 "O vinho e os vinhos - usos e virtudes de um dom dos deuses

nas Enarrationes de Amato Lusitano"

Telmo Corujo dos Reis

2.12 "Amatus Lusitanus e Didaco Pirro: due ebrei portoghesi

e cerchia umanistica di Dubrovnik" 481

Vinicije B. Lupis

2.13 "Estudos contemporâneos sobre Amato Lusitano". 513

João Rui Pita \& Ana Leonor Pereira 


\section{Do carvalho ao castanheiro: usos e propriedades medicinais de fagáceas nas Enarrationes de Amato Lusitano ${ }^{1}$}

EMÍLIA OLIVEIRA²

\section{RESUMO:}

Amato Lusitano dedica os comentários 131-133 do livro primeiro das Enarrationes a árvores como o carvalho, a azinheira, o sobreiro, a faia e o castanheiro. 0 presente artigo tem como objectivo explorar os variados usos e propriedades terapêuticas destas fagáceas.

\section{PALAVRAS-CHAVE:}

Amato Lusitano; Fagáceas; Quercus; Fagus; Castanea.

\section{ABSTRACT:}

Amato Lusitano devotes Comments 131-133 of the first book of Enarrationes to trees such as the oak, the holm oak, the cork oak, the beech and the chestnut tree. This paper aims to explore the varied uses and medicinal properties of these Fagaceae.

\section{KEYWORDS:}

Amato Lusitano; Fagaceae; Quercus; Fagus; Castanea.

1 Este trabalho foi desenvolvido no âmbito do projecto de I\&D "Dioscórides e o Humanismo Português: os Comentários de Amato Lusitano" (http://amatolusitano.web.ua.pt) do Centro de Línguas, Literaturas e Culturas da Universidade de Aveiro, financiado por Fundos FEDER através do Programa Operacional Factores de Competitividade - COMPETE e por Fundos Nacionais através da FCT - Fundação para a Ciência e a Tecnologia, no âmbito do projecto FCOMP-01-0124-FEDER-009102.

2 Centro de Línguas, Literaturas e Culturas da Universidade de Aveiro e Centro de Estudos Clássicos da Faculdade de Letras da Universidade de Lisboa: emilia.oliveira@ua.pt. 
No livro primeiro das Enarrationes de Amato Lusitano, mais concretamente, nos comentários 131-133, o humanista reflecte sobre os usos e propriedades medicinais de algumas árvores pertencentes à família Fagaceae ${ }^{3}$.

Assim, na enarratio $1.131^{4}$, consagrada à descrição das características e virtudes do carva1 ho ${ }^{5}$, Amato inclui outras fagáceas, a saber, a faia ${ }^{6}$, a azinheira ${ }^{7}$ e o sobreiro ${ }^{8}$. Na verdade, como se percebe pelo próprio texto de Dioscórides ${ }^{9}$, o nome grego usado para designar o carvalho, $\delta \rho \tilde{u} \varsigma$, que, em Amato, tem como correspondentes latinos quercus e robur, é um termo genérico que designa não apenas essa, mas outras espécies de árvores produtoras de glande (ou bolota), chamadas glandíferas ${ }^{10}$. Amato confirma-o, dizendo:

3 Agradecemos ao Prof. Doutor Jorge Paiva as informações relativas à classificação das fagáceas que são objecto deste estudo, bem como outras sugestões que tão gentilmente nos foram facultadas. Sobre estas plantas, leia-se Antoine Kremer [et alii], "Genomics of Fagaceae", Tree Genetics 8 Genomes 8 (2012), pp. 583 e seg., onde se diz que as Fagaceae são uma lata família de angiospérmicas (pertencentes à ordem Fagales), que abarca mais de 900 espécies distribuídas por 8-10 géneros, maioritariamente presentes nas zonas temperadas do Hemisfério Norte. Os géneros do carvalho (Quercus), do castanheiro (Castanea) e da faia (Fagus) são os únicos que se encontram distribuídos pela Ásia, Europa e América do Norte e os mais relevantes do ponto de vista económico, já que constituem recursos florestais com inúmeros usos (biomassa, fibra, produtos de madeira e alimentares). Sobre os diferentes géneros e espécies de fagáceas, vide também Antoine KrEMER [et alii], "Fagaceae Trees", in Chittaranjan Kole (ed.), Genome mapping and molecular breeding in plants, vol. 7, Forest Trees. Heidelberg, Springer, 2007, pp. 161 e seg.; Paul. S. Manos, Zhe-Kun Zhou e Charles H. Cannon, "Systematics of Fagaceae: phylogenetic tests of reproductive trait evolution", International Journal of Plant Sciences 162 (2001), pp. 1361 e segs.

4 O nosso estudo centrar-se-á, por conseguinte, na análise das enarrationes 131-133 do Livro I das In Dioscoridis Anarzabei De Materia Medica libros quinque Enarrationes Eruditissimae. Veneza, Gualtiero Scoto, 1553.

5 Quercus robur L., carvalho-comum ou carvalho-roble. Para o estabelecimento dos nomes científicos das espécies botânicas citadas neste estudo, consultámos o manual de Francisca Maria FERnANDES e Luís Mendonça Carvalho, Portugal Botânico de A a Z: plantas portuguesas e exóticas. Lisboa, Lidel, 2003.

6 Fagus sylvatica L. subsp. sylvatica.

7 Quercusilex $L$.

8 Quercus suber $L$.

9 Cf. Diosc. 1.106-106.3.

10 Em especial, as que pertencem ao género Quercus L., mas também o castanheiro (Castanea sativa Mill.). A este propósito, leia-se o comentário de Hermolau BÁRBARO em Hermolai Barbari patricii Veneti \& Patriarchce Aquileiensis Corollarium libris quinque Absolutum. Veneza, Oficina dos irmãos De Gregori, 1516, f. 20v, onde se diz que os Gregos designavam com um único termo (drys) diferentes espécies de árvores glandíferas. Por sua vez, Marcelo VIRGílıo, em Pedacii Dioscoridae Anarzabei De medica materia libri sex. Florença, Herdeiros de Fillippo Giunta, 1518, f. 65V, afirma congregar no mesmo capítulo aquilo que a natureza e, posteriormente, o próprio Dioscórides já haviam congregado, ou seja, as árvores glandíferas: Oniunximus unoque et eodem clausimus capite quae natura primum in eodem genere, mox in historia hic scriptor, postremo melliores graecorum codices coniuncta esse voluerunt. 
Drys vox aequivoca est, omnem arborem glandiferam comprehendens, ut ex Dioscoride in praesentia comprehenditur, cum dicat: astringendi vires quercus omnis habet.

Drys é um termo ambíguo que compreende toda a espécie de árvore glandífera, como se depreende de Dioscórides neste capítulo"11, quando afirma: "Toda a espécie de carvalho tem propriedades adstringentes." 12

Mas se as virtudes das glandíferas podem justificar a sua pertença ao mesmo género, o mesmo não se pode dizer em relação à sua morfologia:

Cuius Dioscorides, tanquam species fagum et ilicem numerat, quod intelligas velim, viribus, secus autem figura, cum multum inter se differant.

Gostaria que soubesses que Dioscórides considera como espécies daquele a faia e a azinheira ${ }^{13}$, por causa das suas propriedades, de forma diferente, no entanto, no que diz respeito ao seu aspecto, pois diferem bastante entre si. ${ }^{14}$

A faia ${ }^{15}$, de facto, apesar de glandífera, produz um fruto diferente da bolota do carvalho, bastante apreciado por alguns animais e outrora consumido pelos homens:

11 Diosc., loc. cit.

12 Na mesma linha de pensamento, defende Pietro Andrea MAtTIOLI, em I discorsi di M. Pietro And. Matthioli sanese, medico del sereniss. principe Ferdinando archiduca d'Austria \& c. ne i sei libri di Pedacio Dioscoride Anazarbeo Della materia medicinale. Veneza, Vincenzo Valgrisi, 1563, p. 145: "Ma perche drys vocabulo Greco, il quale noi interpretiamo quercia nel nostro volgare, serve universalmente et alla quercia, et ad ogni altra specie d'alberi ghiandiferi, comprese Dioscoride sotto questo vocabulo tutte le specie delle piante, che ne producono le ghiande. Et imperò disse egli nel principio del presente capitolo: "Ogni quercia ha virtù costrettiva", quasi volendo dire "Ogni pianta ghiandifera è costrittiva". Il che da ad intendere esser questo capitolo commune à tutti gli alberi sopradetti." Também Andrés LAGUNA, em Pedacio Dioscorides Anarzabeo. Acerca de la materia medicinal y de los venenos mortíferos. Antuérpia, Casa de Juan Latio, 1555, p. 92, afirma: "Este Griego vocabulo drys, que propriamente significa el roble, llamado de los Latinos robur, y quercus, es aqui general y commun à todos aquellos arboles, que produzen bellota. De suerte que lo que aqui atribuye al roble Dioscorides, se deve entender de todas las glandiferas plantas, de las quales ay innumeras differentias."

13 Cf. Diosc. 1.106.2. Na verdade, Dioscórides aplicou o nome de origem indo-europeia da faia, $\varphi \eta \gamma o ́ \varsigma$ (lat. fagus), a qual não existia no espaço geográfico grego, a uma variedade de carvalho nativa do sul da europa (Quercus aegilops L. ou Quercus macrolepsis Kotschy). No seu comentário, porém, Amato parece referir-se à faia (Fagus sylvatica L. subsp. sylvatica), tendo em conta o nome apresentado em diferentes línguas europeias (em Espanhol, 'haia arbore'; em Italiano, 'faggio', 'faggivola'; em Francês, 'faus') e a descrição que faz do respectivo fruto (uma glande triangular).

14 Cf. A. Laguna, op. cit., loc. cit.

15 Fagus sylvatica L. subsp. sylvatica. 
Nam fagus arbor est, quae licet fructum glandi figura et forma similem non habeat, glandiferis tamen annumeratur arboribus, cum fructum ferat viridem aculeatum, intra quem glans dulcissima, triangulari figura includitur, subtili quodam cortice ad rufedinem, cum quodam splendore, veluti in castaneis videtur, cooperta, quam glires et mures avidissime comedunt, et a turdis maxime expetitur; qua quoque homines in victu tantum assumpta diu vixisse feruntur.

Com efeito, a faia é uma árvore que, embora não tenha um fruto semelhante no aspecto e na forma à bolota, se inclui, todavia, no número das árvores glandíferas, já que produz um fruto verde com espinhos dentro do qual se encontra encerrada uma glande dulcíssima de forma triangular, envolta numa fina casca de cor arruivada, um tanto brilhante, tal como a que se vê nas castanhas; os arganazes e os ratos comem-na com muita avidez e é bastante procurada pelos tordos. Diz-se que os homens também se alimentaram exclusivamente dela durante muito tempo. ${ }^{16}$

Por sua vez, a azinheira ${ }^{17}$ apresenta semelhanças com o carrasco (ou carrasqueira ${ }^{18}$ ), mas, por ser maior, segundo Amato, é muitas vezes confundida com outra fagácea, o sobreiro ${ }^{19}$ :

Ilex vero arbor est similis granam ferenti, quae ut diximus procere crescit. Nonnulli tamen illicem maius suber esse crediderunt, sed falso, cum maius suber arbor magnae proceritatis sit, et ex qua cortices virides et sicci, variis rebus accommodati extrahantur. Nam medius cortex, quem viridem appello, colore rubrum, a coriariis Hispaniae pro praeparandis bubulis coriis usurpatur; exteriores vero cortices sive sicci, pro cooperiendis domibus tegularum loco variis in locis accipiuntur, veluti pro conficiendis alvearibus et crepidis ac soccis ornandis.

16 Em P. A. MATTIOLI, op. cit., pp. 145 seg., encontramos a mesma justificação para a inclusão da faia no grupo das glandíferas. 0 comentador descreve o fruto desta árvore em termos muito semelhantes aos de Amato, fazendo igualmente referência ao seu consumo por diversas espécies de roedores (arganazes, ratos e esquilos) e aves (tordos, melros...), assim como pelo homem, em períodos de carestia. A. LaGUNA (op. cit., loc. cit.) descreve desta forma a faia e o respectivo fruto: "Cuentase tambien la haya entre los arboles que produzen bellota, dado que su fructo es de differente figura y forma, el qual se muestra por defuera redondo, velloso, y vestido de muy aspera cascara, dentro de la qual se encierra un meollo duro, y triangular, cubierto de otra cascarilla lisa, y subtil, de color castaño. El qual fructo es dulce y de grato sabor, aunque estiptico al gusto."

17 Quercus ilex L.

18 Quercus coccifera L.

19 Quercus suber $L$. 
A azinheira, na verdade, é uma árvore parecida com a que produz a gră-dos-tintureiros ${ }^{20}$; conforme dissemos, cresce em altura ${ }^{21}$. Alguns, porém, julgaram que a azinheira era um sobreiro de maior dimensão, mas sem razão, já que um sobreiro de maior dimensão é uma árvore de grande porte da qual são extraídas cascas verdes e secas, próprias para diversas $\operatorname{coisas}^{22}$. Com efeito, a casca do meio, de cor vermelha, a que chamo verde é arrancada pelos curtidores de peles da Hispânia para o curtimento de peles bovinas ${ }^{23}$; já as cascas

20 Amato refere-se, muito provavelmente, ao arbusto chamado carrasco ou carrasqueira (Quercus coccifera L., da família das fagáceas), hospedeiro do Kermes vermilio Planchon, também conhecido como grãdos-tintureiros, grã-de-carrasco ou cochonilha-do-carmim. Este, na verdade, é "um insecto do grupo das cochonilhas, que foi utilizado em tinturaria, para dar a cor carmesim a tecidos valiosos, fabricados desde a antiguidade clássica em toda a Europa, principalmente na zona mediterrânica. Em Portugal era vulgar na Arrábida e no Barrocal algarvio, com grandes populações, que permitiram a sua exploração comercial, tendo sido exportado, como matéria corante preciosa, para muitos centros têxteis europeus. Hoje é raríssimo, não só em Portugal, sendo uma espécie em extinção, mas também noutras zonas onde antes era abundante." (M. A. FerReIRA, "Grã-dos-tintureiros - Kermes vermilio Planchon", Boletim Técnico do UIPP-BT/O6 (2010), p. 1). As fêmeas ressequidas de cochonilhas tipo quermes (coccus) vermilio tomam por hospedeiro o arbusto Quercus coccifera L. (chamado, como já referimos, carrasco ou carrasqueira), que se dá no Sul de França, em Espanha e na Grécia. Os machos alados do quermes morrem pouco depois de cópula. As fêmeas, sem asas, quando ainda larvas, fixam-se nas folhas e nos ramos, sugando-os. Crescem rapidamente até ao tamanho de ervilhas (daí, também, os nomes 'baga de quermes', 'baga carmésios', 'grão escarlate', grana chermes, 'quermes tinctorius', etc.). Triturada em pó, esta "baga" é solúvel em água. $\mathrm{O}$ tingimento em escarlate com quermes alcançou grande tradição, existindo, na idade média, em algumas cidades de França e Itália, corporações de tintureiros de escarlate. Na antiguidade era muito caro, mas muito mais barato que a púrpura, que foi suplantada pelo quermes a partir da conquista de Constantinopla, no ano de 1453, pelos turcos (José Miguel F. P. FIADEIRO, O tingimento de materiais têxteis: de arte a ciência (Oração de Sapiência proferida no Dia da Universidade, em 30 de Abril de 1993). Covilhã, Universidade da Beira Interior, 1993, p. 26).

21 Por oposição ao carrasco (ou carrasqueira), que é uma árvore de baixo porte. A propósito, leia-se a enarratio 4.51, dedicada à grã-dos-tintureiros (De grano quod tingendo est), na qual Amato refere que esta é colhida de uma azinheira pequena (quod lentis magnitudine ex ilice quadam parva colligitur); cf. Diosc. 4.48. Para uma descrição mais pormenorizada das características da azinheira e do respectivo fruto, leia-se, por exemplo, A. LAGUNA, op. cit., pp. 92 seg.: "La enzina es arbol harto crecido, y produze hojas semejantes à las del lauro, empero por el ennes blanquezinas. Tiene la corteza castaña, y la madera maciça, dura, fuerte, y algun tanto bermeja. Sus bellotas son mas pequeñas, y mas austeras que las del roble." Este autor também compara a azinheira ao carrasco (loc. cit.): "Hallase una suerte de enzina muy baxa, la qual llaman en Castilla 'carrasco'. La coscoja llamada de Plínio cusculium, tambien es especie de enzina: y cogese della grana, la qual se haze en unas vexiguillas pequeñas, llamadas cocos."

22 P. A. Mattioli (op. cit., p. 146) estabelece ainda uma comparação entre o sobreiro e a azinheira: "Il sovero di frutto, et di frondi è simile all'elice, (...) ma ha la scorza grossissima, ne cresce tanto à un gran pezzo, quanto fa l'elice." Leia-se a mesma comparação em A. LAGUNA, op. cit., loc. cit.: "El alcornoque, de los Latinos llamado suber, es una especie de roble, que ansi en el fructo, como en las hojas, se parece à la enzina. Empero no es tan poblado de ramos, y tiene la corteza sin comparation mas gruessa, de la qual se hazen aquellos andamios, que en castilla suelen llamarse alcorques (...)".

23 A casca dos sobreiros é muito rica em taninos, razão pela qual tem sido usada como adstringente e, sobretudo, no curtimento de peles; em tempos idos, este foi o uso mais rentável do sobreiro, e por esse facto foram destruídas enormes extensões de sobreirais. 
exteriores ou secas são colhidas, em diversos locais, para cobrir, em lugar de telhas, as casas, assim como para construir cortiços e fabricar alcorques e socos. ${ }^{24}$

Amato relembra, pois, que a utilidade desta e de outras árvores que produzem bolota não se resume à alimentação do homem e de outros animais. As diferentes espécies de glandíferas têm, na realidade, propriedades cicatrizantes, reconhecidas, aliás, pelo próprio Galeno:

Haec vero admodum glandifera est, ut plures aliae arbores, porcis dicatae, ut sunt cerrus, aegilops dicta, aesculus, platyphyllos et roboris varia genera, quae omnia constringendi vires habent, adeo ut Galenus roboris foliis vulnus securi inflictum glutinasset, cum eo tempore nullum aliud ad manus adesset medicamen. Sic enim ille tradit libro sexto De facultatibus simplicium medicamentorum.

Esta árvore, na verdade, é, efectivamente, glandífera, à semelhança de muitas outras árvores destinadas aos porcos, como são o cerrus chamado aegilops ${ }^{25}$, o aesculus ${ }^{26}$, o platyphyllos ${ }^{27}$ e as diversas espécies de carvalho ${ }^{28}$, as quais, sem excepção, têm propriedades constringentes, a ponto de Galeno ter cicatrizado com folhas de carvalho um golpe infligido por uma foice, pois naquele momento não havia à mão nenhum outro medicamento. Assim conta, de facto, no livro sexto Sobre as propriedades dos medicamentos simples. ${ }^{29}$

24 Sobre a utilização da cortiça no fabrico de calçado, leiam-se os comentários de A. LAGUNA (op. cit., loc. cit.) e P. A. MATTIOLI (op. cit., loc. cit.). Este evoca também a utilização de bóias de cortiça nas redes de pesca. A primeira tirada da cortiça ocorre entre os vinte e os trinta anos do sobreiro. A extracção do tecido suberoso faz-se mais ou menos de nove em nove anos. Antigamente a cortiça utilizava-se sobretudo na cobertura dos telhados, no fabrico de calçado, na construção de colmeias (cortiços), etc. A madeira de sobro era usada no fabrico de utensílios agrários. Actualmente a casca é o principal aproveitamento do sobreiro, sendo objecto de múltiplas aplicações na indústria e no artesanato. É usada no fabrico de rolhas, colmeias, isolantes, parqué e outros materiais de construção, juntas para automóveis, calçado, papel de cortiça, manufactura de roupa e outros objectos de uso diário. A cortiça queimada (ou carvão de cortiça) é usada no fabrico de tintas e na medicina.

25 Possivelmente, o Quercus cerris L., carvalho-da-Turquia, ou o Quercus aegilops L.

26 Porventura, o Quercus esculus L. Sin. Quercus petraea (Matt.) Liebl., carvalho-pétreo.

27 Talvez se trate do Quercus petraea f. platyphylla (Lam.) O. Schwarz Sin. Quercus petraea (Matt.) Liebl., carvalho-pétreo.

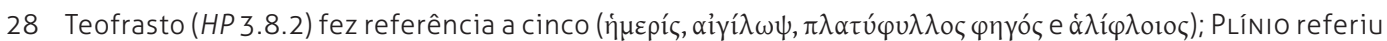
quatro (Nat. 16.16-17: quercus, robur, aesculus e cerrus), mas a identificação das espécies está longe de ser consensual. Leia-se, a este propósito, o comentário de H. BárBARo (op. cit, f. 20v), onde se diz que aos quatro nomes latinos designativos de espécies de carvalho, quercus, robur, aesculus e cerrus, cor-

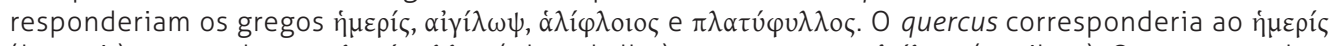
(hemeris), o aesculus ao $\pi \lambda \alpha \tau u ́ \varphi v \lambda \lambda$ os (platyphyllos), e o cerrus ao aỉíi $\omega \psi$ (aegilops). Quanto ao robur, o comentador afirma não ter percebido se corresponderia ou não ao á $\lambda$ í $\varphi \lambda$ oloc (haliphloeos).

29 Cf. Galeno, De simplicium medicamentorum temperamentis ac facultatibus 6.4.11 (Kühn 11.866). 
O carvalho tem, na verdade, propriedades que favorecem a cicatrização de ferimentos:

Exsiccandi, astringendique possidet facultatem cum mediocri quadam tepidaque caliditate:

Tem faculdades dessecativas e adstringentes e uma temperatura um tanto mediana e tépida.

Algumas partes da árvore e do respectivo fruto são, todavia, mais adstringentes do que outras, do mesmo modo que algumas espécies de glandíferas o são relativamente a outras, proporcionando aplicaçóes terapêuticas diversas:

Caeterum plus caeteris eius partibus astringit, quae in trunci cortice membrana subest, tum quae ipsius fructus convestit carnem. Quamobrem ad profluvium muliebre, sanguinis expuitiones, dysenterias et diuturnos ventris fluxus eam esse credunt accommodam. Valentius autem astringunt fagus et ilex.

De resto, mais do que as outras partes deste, adstringe a película que se encontra sob a casca do tronco, tal como a que reveste a carne [sc. semente] do próprio fruto. Por esta razão é que se crê ser apropriada para a hemorragia ginecológica, expectoraçôes de sangue, disenterias e fluxos persistentes do ventre ${ }^{30}$. Contudo, a faia e a azinheira são mais adstringentes. ${ }^{31}$

Já a virtude dessecativa destas árvores é mais concentrada nas folhas e no fruto:

Quarum plantarum folia tenella illita non instrenue desiccant, nec non vulnera glutinant. Eandem foliis vim habet et fructus roboris, eoque medici nonnulli utuntur ad incipientes atque crescentes phlegmonas.

Esfregadas, as folhas um tanto tenras destas plantas secam fortemente e também cicatrizam as feridas ${ }^{32}$. O fruto do carvalho tem a mesma virtude que as folhas

30 Cf. Diosc. 1.106, onde se advoga que o decocto de ambas as partes (o tecido membranoso que se encontra entre a casca e o tronco e o que envolve a bolota debaixo da casca) se deve administrar a quem sofre do ventre, de disenterias e cospe sangue; moídas, aplicam-se em supositório vaginal às mulheres com fluxos menstruais excessivos.

31 Cf. Galeno, op. cit., loc. cit. (Kühn 11.865 e seg.); Diosc. 1.106.1.

32 Cf. Diosc. 1.106.2, onde se diz que as folhas de todas as espécies, uma vez cortadas e moídas, são eficazes contra os inchaços e tonificam as partes afectadas de atonia. 
e, por essa razão, alguns médicos usam-no para as inflamações incipientes e até em desenvolvimento. ${ }^{33}$

Seguindo a tradição botânica que vem desde Teofrasto, na enarratio dedicada ao bugalho (1.133), declara o médico de Castelo Branco:

Fert quercus et eius species glandem et gallam.

O carvalho e as suas espécies produzem a bolota, mas também o bugalho. ${ }^{34}$

Amato distingue três espécies de bugalho ${ }^{35}$. A primeira a que faz referência provém da Síria e tem características muito peculiares:

Quae Syria praecipue affertur, parva, rotunda, in longum tendens, crebis foraminibus perforata, atramento scriptorio conficiendo aptissima.

33 Cf. Galeno, op. cit., loc. cit. Segundo este autor, as inflamações em estado mais avançado não reagem à adstringência do carvalho. Segundo Diosc. 1.106.1, moídas cruas e aplicadas em forma de cataplasma, as bolotas aliviam as inflamações. Misturadas com gordura de porco salgada, revelam-se eficazes contra as indurações rebeldes e úlceras malignas. Pela sua virtude, são mais eficazes as de azinheira que as de carvalho.

34 Segundo este autor (HP 3.7.4), todo o carvalho ( $\delta \rho \tilde{c} \varsigma)$ produz, além da bolota, o bugalho; Cf. Plin. Nat. 16.26, onde se afirma que as árvores glandíferas produzem também o bugalho, e Diosc. 1.107, que defende que o bugalho é fruto do carvalho ( $\delta \rho \tilde{u} \varsigma)$. Leiam-se ainda os comentários de H. BÁrbaro, op. cit., f. 22 r (erradamente numerada como 24), A. LAGUnA, op. cit., p. 95 e P. A. MATTIOLI, op. cit., p. 148. Os bugalhos (ou galhas) são, na verdade, excrescências arredondadas que se formam nos ramos, folhas e inflorescências de algumas espécies de carvalhos, como reacção à picada de um insecto que aí deposita os seus ovos. Com o desenvolvimento da larva, dá-se a proliferação e hipertrofia dos tecidos vegetais e a consequente formação de taninos. As galhas dos ramos dos carvalhos são inicialmente verdes, tornando-se, depois, acastanhadas e volumosas como nozes; as das folhas são verdes e esféricas como ervilhas; as das inflorescências são vermelhas e cilíndricas como pequenos amendoins.

35 Dioscórides (1.107) refere apenas a existência de duas espécies: a primeira, à qual chama ỏ $\mu \varphi \alpha \kappa i ̃ \imath \varsigma$ (isto é, 'semelhante ao sumo de uva verde', devido à sua acritude), é pequena, rugosa, maciça e não perfurada, correspondendo à segunda espécie descrita por Amato); a outra é lisa, leve e perfurada, não sendo certo que corresponda à primeira espécie de bugalho descrita pelo médico albicastrense. P. A. Mattioli (op. cit., p. 149) refere a existência de dois tipos de bugalho: o maior é grande como uma noz, leve e esponjoso; o menor, do tamanho de uma avelã, é rugoso, duro e fechado. Segundo A. LAGUNA, op. cit., p. 95, "Pone aqui dos especies de agallas tan solamente Dioscorides, à las quales se pueden reduzir todas las otras suertes y differentias." Plínio (Nat. 24.9; cf. 16.26), à semelhança do que fizera Teofrasto (HP 3.7.4), foi mais longe, considerando a existência de mais espécies: Nec pauciora gallae genera fecimus, solidam perforatam, item albam nigram, maiorem minorem. A este propósito, leiam-se os comentários de H. BÁrBARO, op. cit., f. 22 r (erradamente numerada como 24) e M. VIRGílio op. cit., f. 65v. Ambos referem a existência de todas essas espécies de bugalho, no entanto, Marcelo Virgílio acrescenta que Teofrasto refere a existência de muitas espécies e que Plínio as retoma a todas, atribuindo nomes latinos a cada uma delas. 
Este [sc. o bugalho] provém principalmente da Síria; é pequeno, redondo, a tender para o alongado, crivado de numerosos furos, muito apropriado para o fabrico de atramento para escrever.'

O segundo tipo de bugalho, apontado como o melhor de todos, tem proveniência e características diferentes:

Nam optima, succosa sit oportet, plena, gravis, styptica, qualis Anconae apud Italos et Castello Albo propria patria nostra apud Hispanos nascitur: unde suaderem, cum galla uti opus fuerit, hac potius recenti quam siccata illa syriaca, uterentur, cum recens omphacitis acerbior et valentior ad omnia, ut diximus, sit.

Na verdade, o melhor [sc. bugalho] convém que seja sucoso, maciço, pesado, adstringente, tal como o que nasce em Ancona, em Itália, e em Castelo Branco, a nossa terra natal, na Hispânia ${ }^{36}$, donde eu aconselharia a que usem, de preferência, sempre que for preciso usar bugalho, este verde em vez daquele seco, da Síria, pois o [bugalho] omphacitis verde é mais acre e eficaz, conforme dissemos, para tudo. ${ }^{37}$

O terceiro tipo de bugalho difere dos anteriores sobretudo na forma:

Est praeterea gallae alia species, magna, circulo veluti corona circundata, caput vitulinum figura repraesentans, non adeo tamen ut altera acerba, ex qua pauperes coronas pro numerandis preculis conficiunt.

36 Amato faz com alguma frequência referências de índole botânica a Itália e à Península Ibérica, em especial, aos locais por onde passou, como Ancona e Castelo Branco.

37 Segundo A. LAGUNA, op. cit., loc. cit., "La agalla omphacitis es aquella pequeñita, y mas estimada que todas, de la qual se haze la tinta fina, yà la qual por este respecto deven mucho todas las disciplinas, y los cultores dellas: la otra es la commun agalla." Os bugalhos são muito ricos em taninos, mais ainda se colhidos antes da saída dos insectos nascidos no seu interior. Os mais célebres tinham origem em Alepo, na Síria, e na Turquia. O ácido gálico deles extraído permitia o fabrico de tintas de muito boa qualidade (os bugalhos, depois de moídos, eram fervidos ou deixados a macerar num líquido ácido: água terçada de vinagre, vinho branco, ou simples vinagre). Por serem ricos em taninos (o seu principal componente é o ácido tânico), os bugalhos também eram usados no curtimento de couros. Apesar de já não terem utilidade na medicina humana, continuam a ser utilizados na indústria de curtumes e corantes. Sobre a utilidade dos bugalhos nos curtumes, na tinturaria, na medicina e na escrita, leiam-se os comentários de H. Bárbaro, op. cit., f. 22 r e M. VIRGílio, op. cit., f. 65v. 
Existe, além disso, outra espécie de bugalho, grande, circundada por um anel semelhante a uma coroa, cuja forma representa a cabeça de um bezerro, mas que não é tão acre como a outra, e com a qual os pobres fazem coroas para contar as oraçôes ${ }^{38}$.

No intuito de corroborar a caracterização que fez dos diferentes tipos de bugalho, evoca a autoridade de Galeno:

De quibus omnibus Galenus libro 7 De facultatibus simplicium medicamentorum memoriam facit, dicens: galla, quae omphacitis dicitur, admodum acerbum est medicamen, pleraque sui parte essentiae terrenae et frigidae, valde desiccat, repercutitque fluxiones. (...) Esto vero tertii in desiccando, secundi autem in refrigerando, ordinis. Altera autem galla, flava illa et magna, laxaque, et ipsa dessicat quidem, sed tanto minus, quanto minus acerbae qualitatis est particeps.

Galeno recorda-as a todas, quando, no livro sétimo Sobre as propriedades dos medicamentos simples, afirma: "o bugalho a que chamam omphacitis é um medicamento bastante acre, na sua maior parte, de essência terrosa e fria, fortemente dessecativo e que repele os fluxos. (...) Na verdade, pode dizer-se que é do terceiro grau dos que dessecam, mas do segundo dos que arrefecem ${ }^{39}$. O outro bugalho, porém, o amarelo, grande e pouco consistente, é também dessecativo, mas tanto menos quanto menos partilha da qualidade acre."

Por fim, explica a utilidade farmacológica do bugalho, decorrente das suas propriedades adstringentes, anti-inflamatórias e hemostáticas:

Cocta itaque ipsa per se in aqua, aut si magis astringere vis, in vino aliquo austero, ac dein trita, cataplasma est non instrenuum sedi inflammatae, procidentique. Gallae combustae, extinctaeque in aceto aut vino, sanguinis reprimendi facultatem acquirunt.

Assim, cozida esta, por si só, em água, ou, se se quiser adstringir mais, num vinho acre, e, em seguida, moída, constitui uma cataplasma eficaz para o ânus inflamado e prolapso. Os bugalhos incendiados e apagados com vinagre ou vinho adquirem a faculdade de estancar o sangue. ${ }^{40}$

38 Amato refere algo semelhante aos actuais terços.

39 Cf. A. Laguna, op. cit., loc. cit., onde se afirma: "Es toda suerte de agalla, seca en el grado tercero, y en el segundo fria."

40 Cf. Galeno, op. cit., loc. cit. Em suma, o bugalho, rico em taninos, tem propriedades adstringentes e dessecativas, sendo variados os seus usos farmacológicos: por via externa, tem uma acção cicatri- 
Na enarratio consagrada à castanha ${ }^{41}$ (1.132), depois de a descrever em termos muito genéricos, Amato explica a origem de um dos nomes atribuídos pelos Gregos a este fruto:

Castanea echinis inclusa nascitur fructus ubique notus, cuius differentiae plures habentur, quas persequi supervacaneum arbitror, dicitur tamen castanea, glans sardiana a Graecis, quia primum Sardibus urbe Asiae inventa.

A castanha, fruto conhecido em toda a parte, nasce encerrada em ouriços; dela encontramos muitas variedades que julgo desnecessário enumerar. Seja como for, a castanha é chamada 'bolota de Sardes' pelos Gregos ${ }^{42}$, porque foi primeiramente descoberta na cidade asiática de Sardes ${ }^{43}$.

Segundo Amato, já Galeno considerava este fruto um alimento bastante nutritivo:

Haec vero, ut tradit Galenus, Libro de cibis boni et mali succi, si in ventriculo concoquatur, efficaciter nutrit, crassique, nunquam tamen mali succi est.

Esta, na verdade, como diz Galeno no Livro sobre os alimentos que provocam bom e mau humor, se é digerida no estômago, nutre eficazmente e provoca humor espesso, mas nunca mau. ${ }^{44}$

Apesar de flatulenta, pode ser bastante saborosa, desde que devidamente condimentada:

Flatuosa tamen castanea est, quae sub cineribus cocta flatum amittit, et optimum, licet siccum, praebet nutrimentum, modo vel saccharo, aut pipere, vel sale comedatur.

zante, hemostática (estanca as hemorragias), protectora e reepitelizante; por via interna, um efeito antidiarreico. Tem ainda uma acção anti-inflamatória e antiséptica; Dioscórides (1.107) aconselha o seu uso, depois de moído, no tratamento de aftas e úlceras da boca, males das gengivas, garganta, anginas e úvula. Segundo o autor, o bugalho, quando introduzido na cárie dos dentes, tem também um efeito analgésico.

41 Fruto do castanheiro-comum (Castanea sativa Mill.), outra árvore da família das fagáceas. Cf. Diosc. 1.106.3.

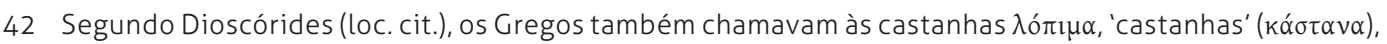

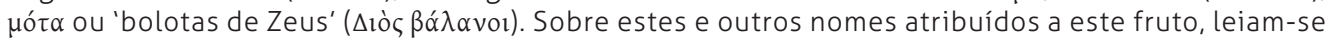
os comentários de H. BÁrbaro, op. cit., f. 21v e M. VIRGílio, op. cit., f. 65v.

43 A capital da Lídia foi uma das mais importantes cidades do império persa. Em 498 a. C., durante a revolta das cidades gregas da Jónia contra os Persas (que teve lugar entre 499 e 493 a. C.), os Jónios, apoiados por tropas de Atenas e de Erétria, capturaram e incendiaram Sardes.

44 Cf. GALENo, De provis pravisque alimentorum succis liber 6.8 (Kühn 6.792 sq.). 
A castanha é, todavia, flatulenta; cozida sob cinzas, liberta gás ${ }^{45}$ e constitui um óptimo alimento, ainda que seco, contanto que seja comida com açúcar, pimenta ou sal. ${ }^{46}$

Seco ao fumo, este fruto tem virtudes medicinais no tratamento de hemorragias ${ }^{47}$. Por outro lado, sendo um importante meio de subsistência, permite, depois de reduzido a farinha, o fabrico de pão ${ }^{48}$ :

Exsiccatae porro ad fumum castaneae sanguinem e pectore fluentem sistunt, ex quibus variae gentes annonae penuria panem parant, inter quas Ligures praecipue nominandi veniunt, cum id genus pane frequentissime utantur.

Além disso, secas ao fumo, as castanhas estancam o sangue que flui do peito ${ }^{49}$. Com elas, na falta de trigo, vários povos confeccionam pão $0^{50}$; entre estes devem ser mencionados em particular os Lígures, pois este povo consome pão abundantemente.

A ambivalência do fruto do castanheiro torna ainda mais evidente a proximidade existente entre esta árvore e as restantes espécies de fagáceas a que anteriormente fizemos alusão, apoiados no texto de Amato. De facto, conforme foi referido, as glandíferas pertencentes aos géneros

45 A castanha é composta por amido e água. Quando o amido é aquecido na presença de água, as partículas que formam os grânulos de amido afastam-se e alguma água penetra no interior dos grânulos que incham. Por sua vez, esta água aquecida passa a vapor, aumentando de volume e fazendo rebentar a castanha se a casca desta não tiver sido previamente cortada.

46 Vide o comentário P. A. MATTIOLI, op. cit., p. 147, onde são referidos os efeitos nefastos do consumo de castanhas. A. LAGUNA, op. cit., p. 94, também refere o valor nutritivo da castanha, mas, ao mesmo tempo, aponta alguns efeitos menos agradáveis inerentes ao seu consumo: "Las castañas, segun Galeno, dan al cuerpo mas nutrimento que ningun otro fructo salvaze: empero engendran ventosidades, hinchan y restriñen el vientre, digerense con difficuldad, provocan el apetito venereo, y comiendose en quantidad, hazen dolor de cabeça."

47 Dioscórides refere as propriedades adstringentes do fruto, em especial, da película que se encontra entre a carne e a casca (cf. 1.106.3).

48 À semelhança, aliás, de alguns tipos de bolota.

49 Segundo P. A. MatTIOLI, op. cit., loc. cit., "ristagnano le castagne, et massime le secche, valentemente i flussi stomachali, et del corpo". Já as castanhas verdes são prejudiciais aos pulmões (cf. A. LAGUNA, op. cit., loc. cit.).

50 Sobre a utilização da castanha no fabrico de pão, leiam-se os comentários de P. A. MATTIOLI, op. cit., loc. cit. e A. LAGUNA, op. cit., loc. cit., Este afirma: "de las castañas secas al humo, y mondadas, se haze cierta harina, que suple por la de trigo, en tiempo de carestia". Não é por acaso que as tribos pré-romanas chamavam ao castanheiro 'árvore do pão'. Antes da introdução da batata e do milho na Europa, este fruto, para muitos povos, foi talvez o mais importante farináceo. Alimentava homens e animais, e, em muitos casos, foi o pão dos mais desfavorecidos. Em anos de produção excedentária de castanha, a que sobrava era transformada em castanha pilada (descascada e seca ao fumo), para posterior consumo. 
Quercus (o carvalho, a azinheira e o sobreiro), Fagus (a faia) e Castanea (o castaneiro) eram usadas na terapêutica de problemas de saúde, mas também na alimentação, ocupando um lugar de relevo na economia doméstica. Estas plantas, na verdade, que produzem frutos valiosos para a subsistência humana e alimentação de outros animais, ainda hoje são determinantes na manutenção do equilíbrio dos ecossistemas que integram e de enorme importância económica para os povos que delas beneficiam ${ }^{51}$.

Os comentários de Amato Lusitano sobre as já citadas glandíferas deixam, no entanto, perceber que a sua utilidade não se resumia - como hoje, aliás, não se resume — à alimentaçáo e à cura de males diversos. O exemplo mais evidente será o do sobreiro, cujo contributo económico assenta principalmente na produção da tão versátil cortiça. Desde tempos idos que a sua casca suberosa é usada no fabrico de calçado, na construção de cortiços, na cobertura de estruturas, na confecção de vedantes (como as rolhas) e numa infinidade de outras aplicaçóes.

A natureza lenhosa destas plantas é outra das suas mais-valias. Em virtude de a sua madeira ser, quase sempre, de muito boa qualidade, à semelhança do que acontecia em tempos recuados, continuam a ser utilizadas na construção de edifícios, no revestimento de superfícies, no fabrico de mobiliário e de inúmeros outros objectos que fazem parte do quotidiano.

Deste modo, tudo o que aqui sobre elas foi referido vem confirmar, uma vez mais, a actualidade da notável obra que o médico e humanista João Rodrigues de Castelo Branco nos deixou.

\section{BIBLIOGRAFIA}

Аmato Lusitano, In Dioscoridis Anarzabei De Materia Medica libros quinque Enarrationes Eruditissimae. Veneza, Gualtiero Scoto, 1553.

Bárbaro, Hermolau, Hermolai Barbari patricii Veneti \& Patriarcha Aquileiensis Corollarium libris quinque Absolutum. Veneza, Oficina dos irmãos De Gregori, 1516.

Dioscórides, Plantas y remedios medicinales (De materia medica): Libros I-III, vol. 1., trad. O. García Valdés. Madrid, Editorial Gredos, 1998.

Fernandes, Francisca Maria; Carvalho, Luís Mendonça, Portugal Botânico de A a Z: plantas portuguesas e exóticas. Lisboa, Lidel, 2003.

Ferreira, M. A., "Grã-dos-tintureiros - Kermes vermilio Planchon”, Boletim Técnico do UIPP-BT/06 (2010), pp. $1-2$.

Fiadeiro, José Miguel F. P., O tingimento de materiais têxteis: de arte a ciência (Oração de Sapiência proferida no Dia da Universidade, em 30 de Abril de 1993). Covilhă, Universidade da Beira Interior, 1993.

Galeno, Opera Omnia, ed. C. G. Kühn, vols. 1-20. Lípsia, Oficina de Carl Cnobloch, 1821-1833.

51 Cf. A. Kremer [et alii], op. cit., 2012, p. 584. 
Kremer, Antoine [et alii], "Genomics of Fagaceae", Tree Genetics \& Genomes 8 (2012), pp. 583-610.

Kremer, Antoine [et alii], "Fagaceae Trees", in Chittaranjan Kole (ed.), Genome mapping and molecular breeding in plants, vol. 7, Forest Trees. Heidelberg, Springer, 2007, pp. 161-187.

Laguna, Andrés, Pedacio Dioscorides Anarzabeo. Acerca de la materia medicinal y de los venenos mortíferos. Antuérpia, Casa de Juan Latio, 1555.

Manos, Paul. S.; Zhou, Zhe-Kun; Cannon, Charles H., "Systematics of Fagaceae: phylogenetic tests of reproductive trait evolution", International Journal of Plant Sciences 162 (2001), pp. 1361-1379.

Mattioli, Pietro Andrea, I discorsi di M. Pietro And. Matthioli sanese, medico del sereniss. principe Ferdinando archiduca d'Austria \& c. ne i sei libri di Pedacio Dioscoride Anazarbeo Della materia medicinale. Veneza, Vincenzo Valgrisi, 1563.

Plínio-o-Velho, Naturalis historia libri XXXVII, ed. lit. K. Mayhoff, vols. 1-6. Estugarda, Teubner, reimp. 1967-70.

Teofrasto, Enquiry into Plants: Books 1-5, trad. A. F. Hort. Cambridge, Harvard University Press, reimp. 1916.

Virgílio, Marcelo, Pedacii Dioscoridae Anarzabei De medica materia libri sex. Florença, Herdeiros de Fillippo Giunta, 1518. 
A partir dos alvores do século XVI, a matéria médica torna-se indiscutivelmente um tema de primeira grandeza entre os membros da República das Letras, objecto de estudo e de controvérsia entre os mais notáveis humanistas europeus, em particular entre os cultores da arte médica. Entre os autores em destaque neste volume encontram-se, à cabeça, os nomes de Amato Lusitano, Garcia de Orta e Nicolás Monardes, famosos pelos contributos valiosos que deram para o conhecimento do mundo natural. 0 volume encontra-se dividido em duas partes: a primeira, subordinada ao título "Humanismo e Ciência", alberga os estudos que versam sobre todos os autores estudados, à excepção de Amato Lusitano; a segunda está reservada a um conjunto de trabalhos dedicados exclusivamente ao médico albicastrense, cuja autoria se fica a dever, em boa parte, aos membros da equipa do projecto de I\&D "Dioscórides e o Humanismo Português: os Comentários de Amato Lusitano", tomando, por isso, 0 seu próprio título. Nesta segunda parte, oferece-se, desde já, aos leitores uma amostra significativa do trabalho desenvolvido no âmbito do projecto e que culminará, assim se espera, na edição e tradução integral para língua portuguesa das quatro obras previstas de Dioscórides, Amato Lusitano e Pietro Andrea Mattioli. 
